\title{
Lab-on-a-Chip System to Monitor the Oxygen Consumption of Mammalian Cells
}

\author{
Frank Bunge $^{1}$, Sander van den Driesche ${ }^{1}$, Anya Waite $^{2}$, Ursula Mirastschijski $^{3}$, Michael J. Vellekoop ${ }^{1}$ \\ ${ }^{1}$ Institute for Microsensors, -actuators and -systems (IMSAS), MCB, University of Bremen Germany \\ ${ }^{2}$ Alfred-Wegener-Institute (AWI), Bremerhaven, Germany \\ ${ }^{3}$ Centre for Biomolecular Interactions, University of Bremen, Germany \\ Email address: fbunge@imsas.uni-bremen.de
}

\begin{abstract}
:
We present a Lab-on-a-Chip system to monitor the uptake of oxygen by mammalian cells during their metabolism. The oxygen consumption indicates the state of the cells and their response to the physical or chemical stimuli and is thus of interest for biological analyses. Although oxygen measurements are topic of investigations for a long time already, such a measurement system is still complex with a high number of external components which hamper their usage for biological researchers. Our system consists of a microfluidic chip with an oxygen sensitive phosphorescent film out of dye PtTFPP in a matrix of polystyrene. All external components of the optical system and the temperature control are low-cost components that are integrated in the assembly. Therefore, the entire system has a small footprint, an easy usage and a high degree of automation. With this system, the oxygen uptake of HaCaT cells is reproducibly measured as 10, 20 and 22 amol/(cell.s) for temperatures of $34^{\circ} \mathrm{C}, 37^{\circ} \mathrm{C}$ and $40^{\circ} \mathrm{C}$.
\end{abstract}

Key words: Lab-on-a-Chip, oxygen sensing, oxygen consumption rate, PtTFPP, phosphorescence

\section{Introduction}

One of the most important characteristics of living mammalian cells is the metabolism where glucose or pyruvate is burned under the uptake of oxygen. The metabolism is influenced by physical or chemical stimuli so that the state of the cells can be monitored by measuring continuously the oxygen concentration in the culture medium.

The oxygen consumption rate (OCR) is in the range of $5-50 \mathrm{amol} /(\mathrm{cell} \cdot \mathrm{s})$ [1] which can only be measured reliably with high cell densities in small, closed chambers that are common in microfluidics. An attractive sensing principle are phosphorescent films where the intensity of the emitted light correlates with the oxygen concentration [2]. The film can be integrated into the chamber [3-5]. Apart from the sensing chip, such a system requires external components for the excitation light source, an optical read-out system, a control unit and a temperature control because the metabolism of cells as well as the phosphorescent film are very temperature sensitive. These components are expensive and bulky such as a microscope or SLR camera or incubators [3,4] which hamper the application in biological labs.
In this contribution, we present a Lab-on-a-Chip (LoC) system that is based on a microfluidic chip with oxygen sensitive luminescent elements and with an integrated heater and temperature sensor. The read-out and the control is realized with a Raspberry $\mathrm{Pi}$ while low-cost LEDs are used to excite the film which results in a compact assembly with a small footprint and without any bulky or expensive external equipment. With this system, the OCR of human keratinocyte cells is determined for different cell concentrations and temperatures.

\section{Design of the System}

The LoC system to measure the concentration of the dissolved oxygen consists of a microfluidic chip out of glass and silicon with an oxygen sensitive film at 5 sensing spots out of PtTFPP which is embedded in polystyrene as described earlier [3]. Additionally, two electrical conductors are patterned on the backside to heat the chip and to measure the temperature based on the resistance change (see fig. 1.) [5].

The chip is clamped into a 3D-printed holder for the microfluidic and electrical connection as shown in fig. 2 [6]. A Raspberry $\mathrm{Pi}$ camera is mounted above the chip to measure the phosphorescent light of the film that is excited 
with a LED with the wavelength of $395 \mathrm{~nm}$. Additionally, the system consists of a Raspberry $\mathrm{Pi}$ as control unit and a small electrical circuit to control the LED and the temperature.

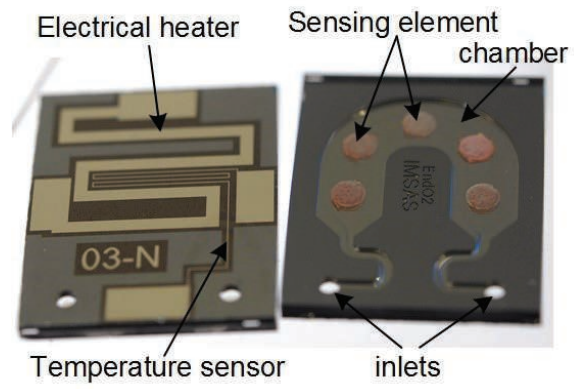

Fig. 1. Back side (left) and front side (right) of the microfluidic chip (dimensions: $9.5 \times 11.5 \times 1 \mathrm{~mm}^{3}$ ) to measure the concentration of dissolved oxygen

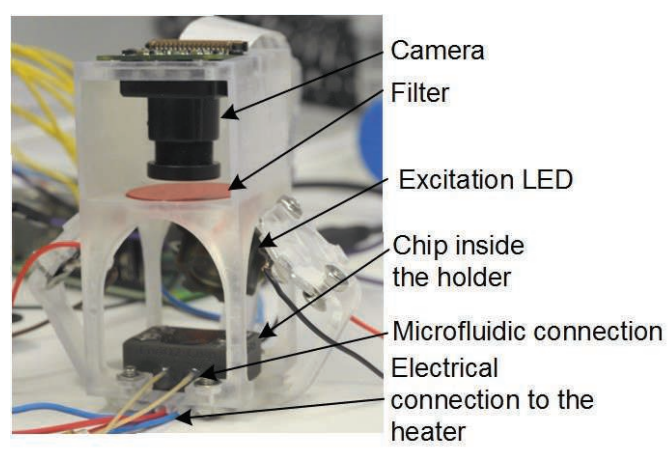

Fig. 2. Assembly of the LoC system to measure the oxygen concentration inside a microfluidic chip (outer dimensions: $68 \times 50 \times 69 \mathrm{~mm}^{3}$ ).

\section{Experiments and Results}

The microfluidic chip is calibrated according to the Stern-Volmer-equation with an error of only $0.6 \%$ (air) in the range between $0 \%$ (air) and $20 \%$ (air). HaCaT-cells with DMEM-medium (cell density $12.9 \pm 1.2 \times 10^{8}$ cell/L) are filled into the microfluidic chip, which is heated to $37 \pm 0.5^{\circ} \mathrm{C}$. The oxygen concentration decreases immediately and within $3.04 \pm 0.06 \mathrm{~h}$ the entire oxygen is consumed (see fig. 3 ). In comparison, the oxygen concentration in pure medium decreased by less than $1 \%$ (air) in this time.

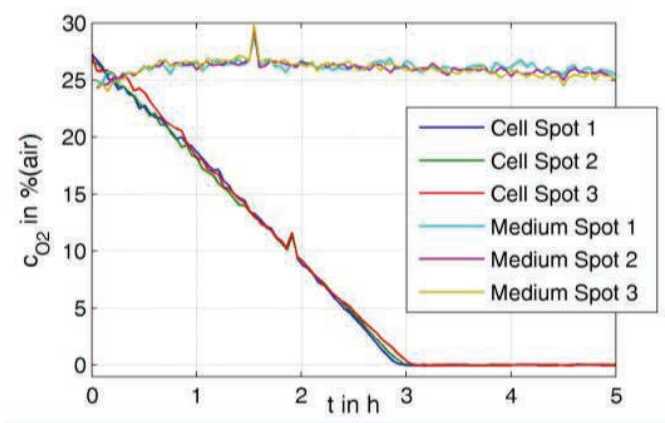

Fig. 3. Measured oxygen consumption of HaCaTcells with a concentration of $12.9 \pm 1.2 \times 10^{8} \mathrm{cell} / \mathrm{L}$ at $37^{\circ} \mathrm{C}$ compared to medium without any cells at 3 different sensing spots.
As shown in fig. 4, the slope of the oxygen concentration correlates with the number of cells. Furthermore, higher temperatures result in higher OCR. In particular, the rates of 10, 20 and $22 \mathrm{amol} /(\mathrm{cell} \cdot \mathrm{s})$ were determined for temperatures of $34^{\circ} \mathrm{C}, 37^{\circ} \mathrm{C}$ and $40^{\circ} \mathrm{C}$.

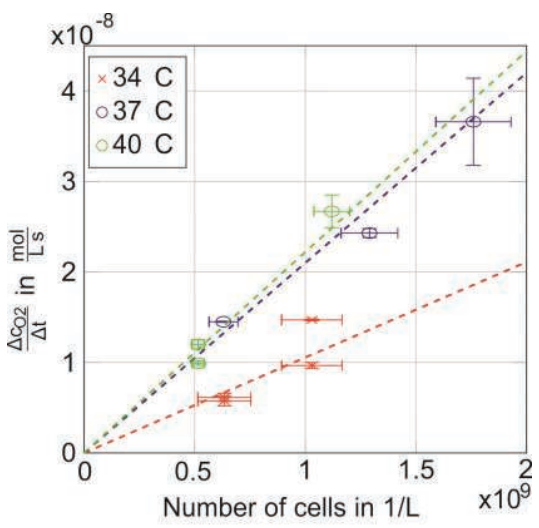

Fig. 4. Correlation between the number of cells and the decrease of the oxygen concentration for different temperatures.

\section{Conclusions}

The presented system is based on a microfluidic chip and small and low-cost optical and electronical components to measure the oxygen consumption of mammalian cells. Because of its simplicity, compactness and ease of use, this lab-on-a-chip system is a major progress to make oxygen sensing systems available for biological researchers.

\section{References}

[1] B. A. Wagner, S. Venkataraman, G. R. Buettner, The rate of oxygen utilization by cells, Free Radical Biol Med, 51(3):700-712, 2011; doi: 10.1016/j.freeradbiomed.2011.05.024.

[2] X. Wang, O. S. Wolfbeis, Optical methods for sensing and imaging oxygen: materials, spectroscopies and applications, Chem. Soc. Rev., 43:3666-3761, 2014; doi: 10.1039/C4CS00039K

[3] F. Bunge, S. van den Driesche, A. Waite, U. Mirastschijski, M. J. Vellekoop, $\mu$ respirometer to determine the oxygen consumption rate of mammalian cells in a microfluidic cell culture, Proc. IEEE MEMS, 414-417, 2017; doi: 10.1109/MEMSYS.2017.7863430

[4] B. Ungerböck, V. Charwat, P. Ertl, T. Mayr, Microfluidic oxygen imaging using integrated optical sensor layers and a color camera. $L a b$ Chip, 13(8):1593, 2013; doi: 10.1039/c3lc41315b

[5] F. Bunge, S. van den Driesche, A. Waite, U. Mirastschijski, M. J. Vellekoop, Microfluidic oxygen sensor based on silica gels for longterm experiments, Proc. IEEE MEMS, 1221-1224, 2018

[6] S. van den Driesche, F. Lucklum, F. Bunge, M. J. Vellekoop, 3D printing solutions for microfluidic chip-to-world connections. Micromachines, 9(2):71, 2018, doi: 10.3390/mi9020071 